\section{Direct magnetic separation of red cells from whole blood}

THE magnetic properties of haemoglobin are well established ${ }^{1}$. The prosthetic group of haemoglobin has a protoporphyrin structure (ferrohaem) in which the iron atom is ionically bound. Consequently there are in deoxyhaemoglobin four unpaired electrons per iron atom leading to a paramagnetic moment of 5.35 Bohr magnetons per haem group. Oxyhaemoglobin on the other hand is diamagnetic. Other iron-containing haemoproteins such as ferrihaemoglobin have been shown by magnetic susceptibility measurements ${ }^{2}$ to possess magnetic moments per haem group which correspond reasonably closely to those predicted from the number of unpaired electrons per iron atom. Consequently red blood cells containing deoxyhaemoglobin when placed in a magnetic field $B_{0}$ (Tesla) with field gradient $\mathrm{d} B_{\mathrm{o}} / \mathrm{d} z$ may be expected to experience a magnetic force $F_{M}$ (Newtons) in the $z$ direction given by

$$
F_{\mathrm{M}}=\left(\chi V / \mu_{\mathrm{o}}\right) B_{\mathrm{o}}\left(\mathrm{d} B_{\mathrm{o}} / \mathrm{d} z\right)
$$

where $\chi$ is the (SI) susceptibility of the red blood cell, $V$ $\left(\mathrm{m}^{3}\right)$ its volume and $\mu_{\mathrm{o}}$ the permeability of free space.

In spite of this known property the only previous recorded attempt by Levine ${ }^{3}$ to increase the sedimentation rate of red cells in whole blood by placing them in a magnetic field gradient was unsuccessful. According to our own estimates this null result is not surprising as for the low field gradient operative in Levine's experiment (approximately $0.1 \mathrm{~T} \mathrm{~m}^{-1}$ ) the force predicted by equation (1) is only a few per cent of the gravitational force experienced by the red cells. The development of a new type of high gradient magnetic separator, as described by Oberteuffer ${ }^{4}$, which enables magnetic field gradients of the order of $10^{4}-10^{5} \mathrm{~T} \mathrm{~m}^{-1}$ to be achieved has led us to reassess the possibility of the magnetic separation of blood components. We believe that we have demonstrated that HGMS can be used an as effective means of separating red cells from whole blood.

In the present experiment a polyethylene cylinder of $60 \mathrm{ml}$ capacity with inlet and outflow arrangement was mounted between the pole-pieces of a conventional electromagnet. Into this cylinder smooth stainless steel wire of circular cross section and $25 \mu \mathrm{m}$ diameter was randomly packed to a volume of $40 \mathrm{ml}$. Approximately $2 \%$ by volume of this $40 \mathrm{ml}$ 'filter' was actually occupied by wire. The length of the filter was less than the diameter of the magnet pole pieces ensuring that the whole wire volume was exposed to a uniform magnetic field. A standard magnetic field of $1.75 \mathrm{~T}$ (17.5 kgauss) was used and the magnetic field gradient close to the wires was estimated to be $8 \times 10^{3} \mathrm{~T} \mathrm{~m}^{-1}$. Isotonic sodium dithionite $\left(\mathrm{Na}_{2} \mathrm{~S}_{2} \mathrm{O}_{4}\right)$ was used both as a reducing agent and as a carrier for the whole blood.

The sample used was whole human blood with ACD anticoagulant in which most of the plasma had been replaced by $\mathrm{Na}_{2} \mathrm{~S}_{2} \mathrm{O}_{4}$ solution. The haemoglobin concentration of this standard sample was $11.8 \mathrm{~g} \mathrm{dl}^{-1}$. The column was first flushed out with $\mathrm{Na}_{2} \mathrm{~S}_{2} \mathrm{O}_{4}$ solution and then with the magnetic field of $1.75 \mathrm{~T}$ switched on, $5 \mathrm{ml}$ of the blood sample was applied to the top of the column. This was followed by $270 \mathrm{ml}$ of $\mathrm{Na}_{2} \mathrm{~S}_{2} \mathrm{O}_{4}$ solution, introduced slowly to maintain the flow rate through the column at approximately $4.5 \mathrm{ml} \mathrm{min}^{-1}$. From the point when the blood was introduced samples flowing from the column were taken as a function of time. After a certain amount of strong discoloration with red cells or haemoglobin the effluent developed an almost transparent pale pink colour. After approximately $175 \mathrm{ml}$ of solution had passed through the column the magnetic field was reduced to zero and successive $5 \mathrm{ml}$ aliquots wera taken. The effluent was observed to change markedly to a deep red colour as the field was

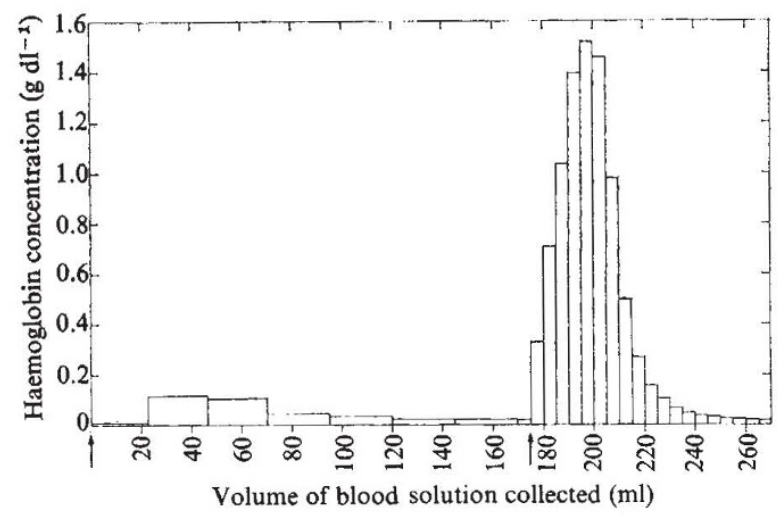

Fig. 1 Haemoglobin concentration of samples as a function of volume flowing through the magnetic separator. First arrow, field on, blood applied; second arrow, field off.

switched off. All aliquots were spun to check for cell lysis and then analysed for haemoglobin content.

Figure 1 shows the measured haemoglobin concentration of the effluent as a function of time throughout the whole experiment. It can be seen that approximately $70 \%$ of the red cells applied to the column were retained until the field was removed. (This implies that $1.30 \times 10^{10} \mathrm{red}$ blood cells were held in the filter.)

Studies of the aliquots showed no evidence in the form of free haemoglobin for immediate red cell destruction. This test was of particular interest as preliminary experiments with 'household' steel wool as the filter medium, although producing similar separation effects, led to a large number of ruptured or severely damaged red cells. The probable reason is that this material possesses an extremely irregular and non-uniform surface.

Scanning electron microscope studies of the cells filtered using the regular stainless steel wire indicated that a small proportion possessed slight morphological abnormalities, mostly in the form of small surface protruberances or indentations. We have yet to determine whether such defects affect the ultimate viability of the red blood cells.

An estimate of the surface area of the filter medium indicates that the wire was completely covered with red celis during the time that the magnetic field was applied. This conclusion is supported by the constant 'hold-back' value of $0.06 \mathrm{~g}$ haemoglobin per $\mathrm{g}$ wire observed in a number of experiments.

In magnetic separation terms the flow velocity used in the present experiment is extremely low $\left(\sim 10^{-4} \mathrm{~m} \mathrm{~s}^{-1}\right)$ and further work is necessary to determine how the filter performance varies with flow rate and applied magnetic field.

The successful outcome of this preliminary experiment indicates that high gradient magnetic separators may be used to produce either blood plasma with a low red cell population, or a suspension of red cells free from other blood contents. It also suggests that other haemoproteins in suitable form may be separated in the same way. The application of this principle to specific research or clinical applications is of interest for further investigation.

D. Melville

Department of Physics,

University of Southampton,

F. PAUL

S. ROATH

Department of Haematology, University of Southampton SO9 5NH, UK

Received March 20; accepted May 14, 1975.

1 Taylor, D. S., and Coryell, C. A., J. Am. Chem. Soc., 60, 1177-1181 (1938) 2 Coryeli, C. A., Stitt, F., and Pauling, L., J. Am. Chem. Soc., 59, 633-42 (1937).

4 Oberteuffer, J. A., IEEE Trans. Magn., MAG-9, 303-306 (1973). 